\title{
Vacunación asistida por pruebas de titulación de anticuerpos en caninos
}

\author{
Tania Guerra Álvarez ${ }^{1} \bowtie$, Ricardo Corrales Viera ${ }^{1}$, Rebeca Solera García ${ }^{1}$
}

1 Centro VIP, Concepción de Tres Ríos, Costa Rica. Email: racviera@gmail.com, tania.guerra@yahoo.com, re.be.k25@hotmail.com

Actualmente es conocido el efecto de la sobre-vacunación en caninos y está demostrado que los niveles de anticuerpos pueden ser más duraderos que los intervalos de revacunación propuestos por los fabricantes.

Se realizó un estudio durante un período de 18 meses, durante el cual se titularon muestras de caninos para anticuerpos contra el virus de la Hepatitis infecciosa canina, Parvovirus y Distemper canino, para lo que se utilizó una prueba con formato DOT-ELISA, de fácil realización en condiciones de clínica. Se tomaron datos referentes a edad, sexo e historial de vacunación y se revacunaron aquellos que mostraban una respuesta negativa o débil de anticuerpos, volviéndose a repetir la titulación cuatro semanas pos vacunación. Se evaluó además la aceptación por parte de los dueños de la realización de la prueba.

Los resultados obtenidos fueron analizados estadísticamente y se evidenció una mayor variación en la respuesta de anticuerpos frente al virus del Distemper canino, así como una respuesta mayor frente al Parvovirus canino. Se determinó una variabilidad en dependencia del historial de vacunación y la exposición, así como individual. Se observó una buena aceptación de la prueba por parte de los clientes, como rutina en los exámenes realizados a sus mascotas.

Después de meses de aplicar esta prueba DOT-ELISA en una clínica y dar seguimiento a los pacientes involucrados, se propone incluirla como parte del esquema de vacunación en caninos en Costa Rica. Este tipo de estudio nos permitirá tener valiosa información en el tiempo para la toma de decisiones en cuanto a esquemas de vacunación en caninos en nuestras condiciones.

凶 Autor para correspondencia Tania Guerra Álvarez: tania.guerra@yahoo.com 